\title{
DÜBLIN
}

Technological University Dublin

ARROW@TU Dublin

\section{Atmospheric Cold Plasma Dissipation Efficiency of Agrochemicals on Blueberries}

\author{
Chaitanya Sarangapani \\ Technological University Dublin, chaitanyakrishna.sarangapani@tudublin.ie \\ Grainne O'Toole \\ Technological University Dublin, grainne.otoole@tudublin.ie \\ Paula Bourke \\ Technological University Dublin, paula.bourke@tudublin.ie
}

See next page for additional authors

Follow this and additional works at: https://arrow.tudublin.ie/schfsehart

Part of the Other Food Science Commons

\section{Recommended Citation}

Sarangapani, C., O'Toole, G., Cullen, P.J. \& Bourke, P. (2017). Atmospheric cold plasma dissipation efficiency of agrochemicals on blueberries. Innovative Food Science and Emerging Technologies. doi:10.1016/j.ifset.2017.02.012

This Article is brought to you for free and open access by the School of Food Science and Environmental Health at ARROW@TU Dublin. It has been accepted for inclusion in Articles by an authorized administrator of ARROW@TU Dublin. For more information, please contact arrow.admin@tudublin.ie, aisling.coyne@tudublin.ie, gerard.connolly@tudublin.ie.

Funder: Department of Agriculture, Fisheries and Food, Ireland. 
Authors

Chaitanya Sarangapani, Grainne O'Toole, Paula Bourke, and Patrick Cullen

This article is available at ARROW@TU Dublin: https://arrow.tudublin.ie/schfsehart/229 
Title: Atmospheric cold plasma dissipation efficiency of agrochemicals on blueberries

Chaitanya Sarangapani ${ }^{1}$, Grainne O'Toole ${ }^{1}$, P.J. Cullen ${ }^{1,2}$, Paula Bourke ${ }^{1 *}$,

${ }^{1}$ Plasma Research Group, School of Food Science and Environmental Health, Dublin Institute of Technology, Dublin 1, Ireland

${ }^{2}$ School of Chemical Engineering, University of New South Wales, Sydney, Australia.

*Corresponding author:

E-mail: paula.bourke@dit.ie 


\begin{abstract}
Cold plasma has emerged as a potential bio-decontamination technology for microbial and chemical risks associated with food products such as fruits and vegetables. This study investigated the efficacy of cold plasma treatment for the degradation of pesticides (boscalid and Imidacloprid) on blueberries in tandem with the need to retain critical quality attributes of a fresh high value berry product post treatment. An in-package high voltage dielectric barrier discharge plasma reactor was employed for this study. The degradation efficacy of pesticides after $80 \mathrm{kV}$ and 5 min of cold plasma treatment were found to be $80.18 \%$ for boscalid and $75.62 \%$ for Imidacloprid. Total phenol and flavonoid contents of blueberries increased significantly for $1 \mathrm{~min}$ treated samples for all applied voltages. However, plasma treatment significantly decreased the ascorbic acid at longer plasma doses. There was no significant effect on physical parameters such as color while acceptable changes were observed in blueberry firmness. This study demonstrates effective chemical decontamination of blueberries whilst maintaining critical nutritional and physical quality parameters, offering an alternative process for quality retention of processing sensitive high value berry products.
\end{abstract}

Key words: Dielectric Barrier Discharge (DBD) plasma, pesticides, degradation, quality. 


\section{Introduction}

Pesticides are a numerous and diverse group of chemical compounds, which are widely used in modern agriculture to control pests and delay crop spoilage. However, issues with pesticide resistance necessitating increased application levels, their residual presence on foods and their persistent effects in aquatic and terrestrial environments cause broad concern. Identified risks associated with fruits and vegetables include food borne pathogens and agrochemical residues. Agrochemicals such as pesticide residues pose a serious health risk on fresh produce, particularly if consumed without washing or are minimally processed. According to data from the European Union's Pesticide Action Network, 209 different pesticides have been detected in food produced in the EU. More than $2 \%$ of food samples tested contained residual pesticide levels exceeding the EUs maximum residue level (MRL). The accidental consumption of pesticide contaminated vegetables was reported in China (Deng, Qu, Huang, Yang, Zheng, \& Wang, 2003). Therefore, as a preventive measure to avoid adverse impacts on human health, effective ways for removal of pesticide residue on fruits and vegetable are required.

Recently, the potential of plasma discharges for pesticide degradation on food and in water was reported (N. Misra, Pankaj, Walsh, O'Regan, Bourke, \& Cullen, 2014; Sarangapani, Misra, Milosavljevic, Bourke, O’Regan, \& Cullen, 2016). Plasma is a partially or wholly ionised state of a gas consisting of positively and negatively charged ions, free electrons, free radicals and intermediate reactive atoms, molecules and UV photons with a net neutral charge (Kogelschatz, 2007). Non-thermal plasmas have demonstrated efficacy in biodecontamination (Ziuzina et al, 2013), treatment of food packaging materials (Pankaj, et al., 2014) and processing of foods (Sarangapani, Devi, Thirundas, Annapure, \& Deshmukh, 2015; Sarangapani, Thirumdas, Devi, Trimukhe, Deshmukh, \& Annapure, 2016). Although there have been several studies on microbial decontamination on fruits and vegetables, there 
are limited reports on pesticide degradation. Mechanistic insights and end product identification are required to ensure that breakdown products are absent or non-toxic. Recently, an inductively coupled plasma (ICP) source was employed for the degradation of dichlorvos and omethoate sprayed onto maize (Bai, Chen, Mu, Zhang, \& Li, 2009; Bai, Chen, Yang, Guo, \& Zhang, 2010). Heo et al. (2014) investigated the efficacy of a dielectric barrier discharge (DBD) plasma for the degradation of pesticides on apples. To promote industrial adoption of atmospheric cold plasma as a sustainable and safe processing technology, comprehensive investigation is needed to ensure optimal microbiological, chemical safety and quality of minimally processed foods. The successful degradation of pesticides on strawberries has been demonstrated (N. Misra, S. K. Pankaj, et al., 2014). Cold plasma has also been reported to retain the quality attributes of fresh produce including cherry tomatoes and strawberries (N. Misra, K. M. Keener, P. Bourke, J.-P. Mosnier, \& P. J. Cullen, 2014; N. Misra, Pankaj, Frias, Keener, \& Cullen, 2015; N. N. Misra, et al., 2014).

Increasing attention has been paid by consumers to the health and nutritional aspects of horticultural products (C. Y. Wang, Chen, \& Wang, 2009). Blueberries are rich source of bioactive such as phenolic compounds (flavanoids, tannins) including their abundant anthocyanins and are also rich in ascorbic acid (Heinonen, Meyer, \& Frankel, 1998). However, due to the production and processing practices commonly applied, blueberries are susceptible to contamination by pathogens and pesticide residues. Winter \& Katz (2011) reported blueberries as one of top most chemically contaminated food commodities, which drives research into alternative mitigation strategies to retain the healthy, fresh and nutritional characteristics of this commodity. With continued increase in the consumption of minimally processed fresh produce, it is a priority to ensure effective intervention strategies are in place to assure product safety combined ideally with shelf-life extension. The objectives of this work are to evaluate the efficacy of cold plasma for dissipation of pesticides on blueberries 
and to quantify the impact of the treatment on the critical nutritional and physical quality attributes.

\section{Materials and Methods}

\subsection{Materials}

Acetonitrile, methanol ( $\geq 99.9 \%$ capillary GC-grade), metaphosphoric acid, acetic acid and high purity (>99.5\%) boscalid and imidacloprid standards were obtained from SigmaAldrich, Ireland. Fresh blueberries were purchased from the local supermarket (Dunnes stores, Dublin, Ireland) and stored under refrigerated conditions.

\subsection{Plasma treatment}

A schematic of the experimental set-up employed is presented in Fig.1. The apparatus consisted of two aluminium plate electrodes of circular geometry (outer diameter $=158 \mathrm{~mm}$ ), one of which was placed under a $2 \mathrm{~mm}$ thick dielectric for grounding and the other, over a 10 mm thick Perspex for the high voltage input. The blueberries were placed within a PET (polyethylene terephthalate) package in the inter-dielectric space. The rigid PET package had dimensions of $150 \mathrm{~mm} \times 150 \mathrm{~mm} \times 35 \mathrm{~mm}$ and also served as a dielectric material. Each container was sealed inside a high barrier Cryovac BB3050 film to retain reactive species post treatment. Atmospheric air was used as the working gas. The electrodes were connected to a high voltage step-up transformer (Phenix Technologies, Inc., USA) whose primary winding receives input at $230 \mathrm{~V}, 50 \mathrm{~Hz}$ and delivers a high voltage output in the range 0-120 $\mathrm{kV}$. Treatment times of 0 (control), 2, 5 min at 60 and $80 \mathrm{kV}$ were tested for pesticide degradation study and for the quality parameters 0 (control), 1, 5 min were optimized from preliminary studies. Following treatment, the containers were stored at $16{ }^{\circ} \mathrm{C}$ for $24 \mathrm{~h}$ storage to ensure that the reactive species generated reacted with the samples. Treatment of all samples was carried out in duplicate and at ambient temperature $\left(25 \pm 2{ }^{\circ} \mathrm{C}\right)$. 


\subsection{Exposure of blueberries to pesticides}

Individual pesticide standards were prepared in methanol at $10 \mathrm{ppm}$ concentration each. To ensure a homogeneous distribution of pesticides on the fruit surface Blueberries were immersed into the pesticide solution as described in Misra et al. (2014).

\subsection{Analysis of pesticides}

Standard curves for the tested pesticides were established using pesticide standard solutions ranging between $0.05 \mathrm{mg} / \mathrm{L}$ and $10 \mathrm{mg} / \mathrm{L}$. The linear correlation coefficients $\left(\mathrm{r}^{2}\right)$ were 0.997 and 0.998 for boscalid and imidacloprid respectively. Each sample was extracted by $50 \mathrm{~mL}$ methanol for two times.

The quantification of pesticides was determined using a HPLC system which consisted of a Waters 600 Satellite connected to a Waters 996 PDA detector and Waters auto-sampler (Waters, Ireland). Separation was carried out on a Phenomenex Gemini-Nx C18 column (Phenomenex, U.K.), $5 \mu \mathrm{m}$ particle size $(250 \mathrm{~mm} \times 4.6 \mathrm{~mm})$. The mobile phase consisted of $70 \%$ acetonitrile and $30 \%$ water, and the flow rate was set at $0.6 \mathrm{~mL} / \mathrm{min}$. The detector wavelength was set in the range 210-400 $\mathrm{nm}$. Chromatographic data was collected and processed using Empower2 software (Waters, Ireland).

GC-MS analysis was performed to analyze the degradants. A Varian 3800 GC (JVA analytical Ltd. Ireland) with a 2200 Varian ion trap MS was used to analyze the samples. The compounds present were identified based on correlation with commercial NIST libraries and spectral library of pure substances and available literature.

\subsection{Evaluation of blueberry quality after cold plasma treatment}

\subsubsection{Physical quality parameters}

\subsubsection{Firmness}

The firmness of control and treated samples was analyzed using an Instron texture analyzer (Instron 4302 Universal Testing Machine, Canton, MA, USA). The texturometer was 
mounted with a $500 \mathrm{~N}$ load cell and equipped with a $2 \mathrm{~mm}$ flat head stainless steel cylindrical probe which punctures the sample at a download speed of $200 \mathrm{~mm} / \mathrm{min}$ over a distance of 10

mm. A single blueberry was placed on the stage for each measurement. The maximum force (N) required to puncture the sample was used as an indication of firmness. Data were analysed using Bluehill software (N. Misra, K. M. Keener, et al., 2014; N. N. Misra, K. M. Keener, P. Bourke, J.-P. Mosnier, \& P. J. Cullen, 2014). The firmness of 3 blueberries from each package was individually measured and an average firmness value reported.

\subsubsection{Color analysis}

The color of the blueberry samples were analyzed using a HunterLab spectrophotometer using the parameters $\mathrm{L}^{*} \mathrm{a}^{*}$ and $\mathrm{b}^{*}$. A D65 illuminant was used as a light source with d $/ 8^{\circ}$ geometry. A standard white plate was used to calibrate the spectrophotometer. Each sample was analyzed three times.

\subsubsection{Total soluble solids (TSS)}

Total soluble solids (TSS) concentrations of all of the blueberry samples were measured using a handheld refractometer (Brix meter) (Delta refractometer code $20-50$ range $0-15 \%$ sugar w/w, Bellingham \& Stanley Limited, England). A small amount of juice from the blueberry samples was placed on the refractometer and the readings were taken. Triplicate measurements were taken for each sample and the results were averaged. 


\subsubsection{Titratable acidity}

The titratable acidity (TA) was determined potentiometrically using $0.1 \mathrm{~N} \mathrm{NaOH}$ to an end point of $\mathrm{pH} 8.1$ in $5 \mathrm{~mL}$ of juice diluted in $50 \mathrm{~mL}$ of distilled water. Results were expressed as meq/L.

\subsubsection{Chemical quality parameters}

\subsubsection{Extraction of polyphenols}

The method used for extraction of polyphenols was based on the method of Alothman et al., (2010) with minor modifications. $100 \mathrm{~g}$ of each blueberry sample was blended for 2 min using a commercial hand blender (Kenwood, Dublin). The polyphenols were extracted from the samples using $300 \mathrm{~mL}$ of $90 \%$ methanol organic solvent. A magnetic stirrer was used to make a homogenous mixture; stirred for $20 \mathrm{~min}$ at room temperature. The samples were then filtered and centrifuged for $15 \mathrm{~min}$ at $4750 \mathrm{rpm}$. The supernatant was filtered and stored in the refrigerator at $3^{\circ} \mathrm{C}$. After $3 \mathrm{~h}$ the crude extracts were collected and stored at $4^{\circ} \mathrm{C}$ in the dark.

\subsubsection{Determination of total phenolic content (TPC)}

The method selected to determine total phenolic content of blueberries was that described by Singleton et al. (1999). A calibration curve was processed using a standard solution of Gallic acid. In this experiment the results are expressed on a fresh weight basis (FW) as mg gallic acid equivalents (GAE)/100 g sample.

\subsubsection{Determination of total flavonoids (TFC)}

The method used to determine TFC was based on that developed by Zhishen et al., (1999). A calibration curve was prepared using a standard solution of catechin. In this experiment the results are expressed on a fresh weight (FW) basis as mg catechin equivalents (CEQ)/100 $\mathrm{g}$ samples. 


\subsubsection{Ascorbic acid content}

The ascorbic acid content of blueberry samples was analyzed by HPLC of the method described by Uckoo et al., (2013). Portions (10 g) of blueberry samples were homogenized with $10 \mathrm{~mL}$ of $3 \%$ metaphosphoric acid for 5 min using a commercial blender (Kenwood). After extraction, the samples were centrifuged at $8000 \mathrm{rpm}$ for $15 \mathrm{~min}$ and the clear supernatant was filtered through $0.45 \mathrm{~mm}$ membrane filter and this filtered supernatant was used for HPLC analysis. Similar HPLC set up mentioned earlier was also used for ascorbic acid analysis. The mobile phase consisted of $3 \mathrm{mM}$ meta phosphoric acid in water, and the flow rate was set at $0.6 \mathrm{~mL} / \mathrm{min}$. The detector wavelength was set in the range $210-400 \mathrm{~nm}$. Chromatographic data was collected and processed using Empower2 software (Waters, Ireland). A calibration curve was processed using a standard solution of ascorbic acid. Results are expressed on a FW basis as mg ascorbic acid equivalents (AAE)/100 g sample.

\subsubsection{Anthocyanin content}

The ascorbic acid content of blueberry samples was analyzed by HPLC using the method described by Misra et al.(2015).

\subsection{Statistical analysis}

The results were statistically analyzed by two-way ANOVA using SPSS (IBM statistical analysis Version 19), and the significance among the samples was compared at $P<0.05$ by the least significant difference post-hoc comparison, SPSS 19 version. All the results represent the average of three separate experiments.

\section{Results and discussion}

\subsection{Quantification of Pesticide degradation}

The dissipation efficacy of pesticides, namely boscalid and imidacloprid, on blueberries is shown in Fig.2. The concentration of pesticides in the controls was found to be $1400 \mathrm{ppb}$ and $1100 \mathrm{ppb}$ respectively. Significant degradation was observed $(p \leq 0.05)$ for plasma parameters 
of treatment time and applied voltage. The plasma treatment for 2 min achieved a removal efficiency of more than $20 \%$ at all applied voltage. The removal efficiencies increased to $75 \%$ and $80 \%$ for boscalid and imidacloprid respectively, at $80 \mathrm{kV}$ for $5 \mathrm{~min}$ of plasma treatment. Similar results were observed for the degradation of pesticides in water and on strawberries (N. Misra, S. K. Pankaj, et al., 2014; Sarangapani, Misra, et al., 2016) by plasma treatment. In order to understand the systematic analysis of pesticide degradation on fresh produce first order kinetics was employed to model the reaction. The results shown in Table $\mathbf{1}$ suggest that the model is in agreement with the experimental data for degradation, with the correlation coefficients $>0.90$. Clearly, it can be observed that rate constant increases in tandem with applied voltage. Electrical discharges in air produce exited species such as and $\mathrm{O}^{*},{ }^{\circ} \mathrm{OH}, \mathrm{N}^{\bullet}, \mathrm{HO}_{2}{ }^{-}, \mathrm{N}_{2}{ }^{*}, \mathrm{~N}^{*}, \mathrm{OH}^{-}, \mathrm{O}_{2}^{-}, \mathrm{O}^{-}, \mathrm{O}_{2}^{+}, \mathrm{N}_{2}^{+}, \mathrm{N}^{+}$, and $\mathrm{O}^{+}$(Dojčinović, et al., 2011) which undergo several chain reactions to form metastables including ozone and hydrogen peroxide which have been identified as key species in the degradation of pesticides $(\mathrm{N}$. N. Misra, Keener, Bourke, \& Cullen, 2015; N.N. Misra, Ziuzina, Cullen, \& Keener, 2013; Moiseev, et al., 2014; Sarangapani, Misra, et al., 2016). The increased efficacy found with applied voltage is attributed to the associated increase in intensity of discharge electric field leading to greater amounts of reactive species generated (Gao, Sun, Wan, Yu, \& Li, 2013).

High levels of ozone were detected immediately after plasma treatment. The ozone concentrations measured after 5 min of plasma treatment were found to be 1800 and 2600 ppm (within $\pm 10 \%$ errors) for applied voltages of 60 and $80 \mathrm{kV}$ respectively. Ozone can also undergo reaction with water to yield peroxide and hydroxyl radicals. Among several plasma species ozone and hydroxyl radicals are considered as key active species responsible for the degradation of the pesticides. The degradation mechanism of pesticides by ozone is well established (Hwang, Cash, \& Zabik, 2001; Karaca, Walse, \& Smilanick, 2012; Reynolds, Graham, Perry, \& Rice, 1989). Karaca et al., (2012) reported on the effects of ozone (0.300 
$\mu \mathrm{L} / \mathrm{L}$ ) storage of seedless table grapes for up to 36 days with reductions of $46.2 \%, 23.9 \%$, $64.5 \%, 34.7 \%$, and $51.6 \%$ in the concentrations of Boscalid, Iprodione, Fenhexamid, Cyprodinil, and Pyrimethanil respectively. The removal of fenitrothion from lettuce, tomatoes and strawberries using continuous ozone micro-bubbled solutions was reported by (Ikeura, Kobayashi, \& Tamaki, 2011). Wu et al., (2007) demonstrated the efficient reduction of pesticide on leafy vegetables using ozonated water washing. These active species $\left(\mathrm{O}_{3},{ }^{\circ} \mathrm{OH}\right.$ and $\mathrm{H}_{2} \mathrm{O}_{2}$ ) along with others selectively react with certain functional groups of pesticide, whereas an indiscriminate reaction occurs with the hydroxyl radical (Von Gunten, 2003). In this study, the degradation of boscalid is likely due to attack of hydroxyl radicals at $-\mathrm{H}$ in the three rings (benzene and pyridine rings) leading to four mono and di hydroxylated products and other carboxylic acids (Lagunas-Allué, Martínez-Soria, Sanz-Asensio, Salvador, Ferronato, \& Chovelon, 2010). Furthermore, the suggested degradation of imidacloprid is due to the reaction of hydroxyl radicals to form 6-chloronicotinic aldehyde and 6-chloronicotinic acid (Agüera, Almansa, Malato, Maldonado, \& Fernández-Alba, 1998; Malato, et al., 2001). Critically it may be noted that the end-points of the degradation process are characterized by simpler chemical groups. This indicated that these two pesticides were degraded through different mechanisms.

\subsection{Physical quality parameters}

The effect of cold plasma treatment on the visual appearance, surface color, firmness, and total soluble solids was measured after $24 \mathrm{~h}$ of post treatment storage time. Visual inspection showed that there were no signs of physical damage or visual change in color even after 80 $\mathrm{kV}$ for 5 min. Firmness is a physical quality parameter that relates to the degree of ripeness but also as an indicator of proper handling and consumer acceptability. The firmness of plasma treated blueberries are presented in Table 2. A significant decrease $(p<0.05)$ in the firmness was observed between the control and plasma treated samples. The firmness value 
of the control sample $(1.92 \mathrm{~N})$ was significantly higher than sample treated at $80 \mathrm{kV}$ for 5 min $(0.64 \mathrm{~N})$. Similar decreases in firmness were reported in plasma treated cherry tomatoes and blueberries (Lacombe, et al., 2015; N. Misra, K. M. Keener, et al., 2014). The decrease in firmness is attributed to softening of the surface or damage to the outermost cells as a consequence of the degradation of the internal structures (Tappi, et al., 2016). Lacombe et al. (2015) reported on the loss of firmness in dry air plasma treated blueberries which was attributed to mechanical damage and/or an increase in temperature during treatment.

Color plays a key role in food choice and is the most important parameter for consumer acceptability. Blueberry color is a complex quality characteristic affected by the anthocyanin content combined with the quantity and structure of surface waxes. Table 2 shows the changes in $\mathrm{L}^{*}, \mathrm{a}^{*}, \mathrm{~b}^{*}$ color parameters of cold plasma treated blueberries. It can be observed that the mean $L^{*}, a^{*}, b^{*}$ values of the control samples $48.90,0.30,-1.19$ were higher than the treated blueberries. The results also show that the $a^{*}$ values for plasma treated blueberries tended to move towards red and that the $b^{*}$ values for plasma treated blueberries tended to move towards blue. However, statistical analysis showed that these differences are not significant $(p>0.05)$ compared with the control sample. These results are in agreement with those of cold plasma treated strawberries and cherry tomatoes where changes in color among the control and treated groups were found to be insignificant (N. Misra, K. M. Keener, et al., 2014; N. N. Misra, et al., 2014). The only significant difference $(p<0.05)$ observed was in blueberries sample treated at $80 \mathrm{kV}$ for 5 min with the lowest mean $\mathrm{L}^{*}, \mathrm{a}^{*}$, and $\mathrm{b}^{*}$ values of $43.76,0.23$, and -1.43 were recorded. A decrease in the $L^{*}$ value results in darkening of fruits (Bialka \& Demirci, 2007). Similar results were observed in dry air plasma treated blueberries (Lacombe, et al., 2015). Bermúdez-Aguirre et al. (2013) reported that the possibility of degradation of carotenoid pigments by reactive species resulted in significant changes in the color of cold plasma treated tomatoes. The darkening in blueberries is attributed to melting of 
cutaneous wax on the surface of blueberries and loss of surface moisture (Lacombe, et al., 2015; R. Wang, et al., 2012).

There was no significant difference $(\mathrm{p}>0.05)$ for titratable acidity (TA) in the plasma treated samples. Similarly, Won et al., (2017) found no significant differences for titratable acidity in control and cold plasma treated mandarins. Total soluble sugar of plasma treated samples are shown in Table 1. A significant increase in TSS values were observed in plasma treated samples and control samples. The TSS value of blueberry samples was enhanced post plasma treatment with the highest value of $14.10^{\circ}$ brix was found in samples treated at $80 \mathrm{kV}$ for $5 \mathrm{~min}$.

\subsection{Chemical quality parameters}

\subsubsection{Total phenolic content (TPC) and total flavonoid content (TFC)}

Table 3 shows the voltage and time dependent changes in the total phenolic content (TPC) and total flavonoid content (TFC) of cold plasma treated blueberries. It can be noted that compared to the control samples, TPC and TFC of blueberries increased significantly $(p<0.05)$ in response to $1 \mathrm{~min}$ of plasma treatment. There was slight reduction in both TPC and TFC for all 5 min treated samples at all applied voltages. The results in this study are in agreement with reports of (Garofulić, Jambrak, Milošević, Dragović-Uzelac, Zorić, \& Herceg, 2015), where the authors also reported the reduction of both anthocyanins and phenolic acids in sour cherry Marasca (Prunus cerasus var. Marasca) juice at longer exposures to plasma treatment. The increase in TPC and TFC can be attributed to activation of phenylalanine ammonialyase, one of the key enzymes in the synthesis of phenolic compounds (C. Y. Wang, et al., 2009). González-Aguilar et al. (2007) reported that the activation of this enzyme in mango fruits is strongly correlated with increases in the phenolic content of the fruits. Brandenburg et al. (2007) suggested a theory governing the direct reaction of plasma species with phenolic compounds such as hydroxyl radicals, peroxyl 
radicals, atomic oxygen and singlet oxygen. The indirect reaction of UV and shock waves might also increase the activity of phenylalanine ammonialyase which would in turn result in increase in phenolic compounds (Stevens, et al., 1996). The increase in the phenolic and flavonoid content of blueberries have also been attributed to depolymerization and dissolution of cell wall polysaccharides, which facilitates higher extraction of the conjugated phenolic compounds (Alothman, Kaur, Fazilah, Bhat, \& Karim, 2010; Grzegorzewski, Ehlbeck, Schlüter, Kroh, \& Rohn, 2011; Sarangapani, Thirumdas, et al., 2016). The interactions of atmospheric plasma reactive species with secondary plant metabolites in lamb's lettuce by Grzegorzewski et al. (2011) suggested that $\mathrm{OH}, \mathrm{O}$ and $\mathrm{O}_{2}$ species may lead to the erosion of the epidermal layer of lettuce where flavonoids and other compounds accumulated in the central vacuoles of guard cells and epidermal cells are released and degraded. Moreover, the reduction in TPC and TFC at higher treatment times might be due to reactive species which were scavenged by phenolic compounds in the blueberries and also cleavage of the central heterocycle in the polyphenolic skeleton and oligomerization (Makris \& Rossiter, 2002).

\subsubsection{Ascorbic acid content}

Ascorbic acid is a nutritional parameter for fresh fruits. The ascorbic acid content of the control and plasma treated sample is shown in Fig.3 (a). It can be observed that both treatment time and applied voltages were found to have significant effect $(p<0.05)$ on ascorbic acid content. The ascorbic acid content of blueberry samples was enhanced post plasma treatment with the highest value of $14.01 \mathrm{mg} / 100$ for $80 \mathrm{kV}$ for $1 \mathrm{~min}$ compared with $8.91 \mathrm{mg} / 100 \mathrm{~g}$ for control samples. As an antioxidant, ascorbic acid plays a significant role in formation of different ROS, such as hydrogen peroxide $\left(\mathrm{H}_{2} \mathrm{O}_{2}\right)$, superoxide radicals $\left(\mathrm{O}_{2}^{-}\right)$, and hydroxyl radicals $(\mathrm{OH} \bullet)$ inside the plant cell and also protects the plant from injuries (Moldau, 1998).Tiwari et al. (2008) reported that ascorbic acid is thermolabile and highly 
sensitive to various processing and storage conditions. Alothman et al. (2010) reported that decreases in anthocyanin content is due to the scavenging of free radicals formed during decomposition of ozone. Similar losses of ascorbic acid have been observed in cut carrots, cucumber and pears after plasma treatment (R. Wang, et al., 2012). A number of studies (Enami, Hoffmann, \& Colussi, 2008; García-Viguera \& Bridle, 1999) have indicated that the degradation of ascorbic acid by ozone is more likely due to direct reaction or by the Criegee mechanism to form ozonide or free radical mechanism by singlet oxygen (N. Misra, et al., 2015). Comparably, ozonation and UV-C treatment of fresh cut fruits have also showed a decrease in ascorbic acid content (Alothman, Bhat, \& Karim, 2009; Alothman, et al., 2010).

\subsubsection{Anthocyanin content}

Anthocyanins reside in vacuoles mostly found on the skin of blueberries. Anthocyanins are commonly promoted for their health effects. The effect of plasma treatment on the anthocyanin content is shown in Fig.3. Anthocyanin content of control samples was found to be $98.37 \mathrm{mg} / 100 \mathrm{~g}$, with a significant reduction $(p<0.05)$ in anthocyanin content observed with extended cold plasma treatment at the higher voltage level. It was known that very different gaseous environments can be found for different voltages and treatment times These differences in anthocyanin content is attributed to dynamic behavior of species forming, quenching and decaying (Moiseev, et al., 2014). Tiwari et al. (2008) also reported a reduction in the cyanidin-3-glucoside content of blackberry juice after 6 min of ozone treatment. Similarly reductions in anthocyanin content of plasma treated blueberries were observed by Lacombe et al. (2015). Active species especially ozone and hydroxyl radical are likely to cause oxidative cleavage of chromophores resulting in significant losses of anthocyanins (Tiwari, et al., 2008). Relatively low diffusion of gas phase ozone (and other reactive species of plasma) into the interiors of fruit tissue may result in such minor effects in anthocyanin content. It is known that the color of blueberries is directly related to anthocyanins. A 
significant change in the colour of plasma treated blueberries at $80 \mathrm{kV} 5 \mathrm{~min}$ was observed along with the change in anthocyanin content.

One of the health concerns of using advanced oxidation techniques such as cold plasma to degrade agrochemicals is the possible formation of toxic intermediates or end products. Other studies have reported that the degradation of chemical contaminants yielded non-toxic intermediates and end products (Boehm, Heslin, Cullen, \& Bourke, 2016; Gao, et al., 2013; Sarangapani, Misra, et al., 2016). It can also be noted that, ozone and other oxidants produced during plasma or post plasma treatment can speed up the mineralization process for complete degradation of the toxic intermediates and ultimately lead to the formation of $\mathrm{CO}_{2}$ (Reddy, Mahammadunnisa, \& Subrahmanyam, 2014). In our study cold plasma treatment was found to degrade the target pesticides and also retain key quality attributes. Employing a short treatment time with a lower applied voltage can maintain critical quality and even enhance some nutraceutical properties, however further process optimization may be necessary to remove concentrations of residual pesticides above the Maximum Residue Limit (MRL) with short treatment times. Future studies will address the feasibility for scale-up of this technology for fresh produce processing. As an environmental friendly technology this process would provide complimentary benefits of microbial safety assurance and shelf life extension.

\section{Conclusions}

Cold plasma successfully degraded pesticide residues on blueberries, with removal efficiencies of $75 \%$ and $80 \%$ for boscalid and imidacloprid respectively, after $80 \mathrm{kV}$ for $5 \mathrm{~min}$ of plasma treatment. The degradation of both pesticides followed first-order kinetic reactions. Acceptable changes in the measured quality attributes were observed for the treatment conditions employed. These results indicate that cold plasma treatment for up to $5 \mathrm{~min}$ at 60 $\mathrm{kV}$ and $1 \mathrm{~min}$ for $80 \mathrm{kV}$ can be employed to retain the nutritional properties of blueberries. 
Thus, cold plasma is a promising technique not only for biocontrol but also for agrochemical decontamination on fresh produce whilst maintaining desirable nutraceutical properties.

\section{Acknowledgment}

The funding for this research was provided by the Food Institutional Research Measure (FIRM) project entitled 'Innovation Process technologies for the fresh produce industry' (project number: 13/F/444) under the National Development Plan administered by the Department of Agriculture, Fisheries and Food, Ireland.

\section{References}

Agüera, A., Almansa, E., Malato, S., Maldonado, M., \& Fernández-Alba, A. (1998). Evaluation of photocatalytic degradation of imidacloprid in industrial water by GC-MS and LC-MS. Analusis, 26(7), 245-250.

Alothman, M., Bhat, R., \& Karim, A. (2009). UV radiation-induced changes of antioxidant capacity of fresh-cut tropical fruits. Innovative Food Science \& Emerging Technologies, 10(4), 512-516.

Alothman, M., Kaur, B., Fazilah, A., Bhat, R., \& Karim, A. A. (2010). Ozone-induced changes of antioxidant capacity of fresh-cut tropical fruits. Innovative Food Science \& Emerging Technologies, 11(4), 666-671.

Bai, Y., Chen, J., Mu, H., Zhang, C., \& Li, B. (2009). Reduction of dichlorvos and omethoate residues by $\mathrm{O} 2$ plasma treatment. Journal of agricultural and food chemistry, 57(14), 6238-6245.

Bai, Y., Chen, J., Yang, Y., Guo, L., \& Zhang, C. (2010). Degradation of organophosphorus pesticide induced by oxygen plasma: effects of operating parameters and reaction mechanisms. Chemosphere, 81(3), 408-414.

Bermúdez-Aguirre, D., Wemlinger, E., Pedrow, P., Barbosa-Cánovas, G., \& Garcia-Perez, M. (2013). Effect of atmospheric pressure cold plasma (APCP) on the inactivation of Escherichia coli in fresh produce. Food Control, 34(1), 149-157.

Bialka, K., \& Demirci, A. (2007). Decontamination of Escherichia coli 0157: H7 and Salmonella enterica on Blueberries Using Ozone and Pulsed UV-Light. Journal of Food Science, 72(9), M391-M396.

Boehm, D., Heslin, C., Cullen, P. J., \& Bourke, P. (2016). Cytotoxic and mutagenic potential of solutions exposed to cold atmospheric plasma. Scientific reports, 6 .

Brandenburg, R., Ehlbeck, J., Stieber, M., Zeymer, J., Schlüter, O., \& Weltmann, K. D. (2007). Antimicrobial Treatment of Heat Sensitive Materials by Means of Atmospheric Pressure RfDriven Plasma Jet. Contributions to Plasma Physics, 47(1-2), 72-79. 
Deng, L., Qu, H., Huang, R., Yang, Y., Zheng, X., \& Wang, H. (2003). Survey of food poisoning by organosphorus pesticide at an employee refectory. Practical Preventive Medicine, 10(5), 766-767.

Dojčinović, B. P., Roglić, G. M., Obradović, B. M., Kuraica, M. M., Kostić, M. M., Nešić, J., \& Manojlović, D. D. (2011). Decolorization of reactive textile dyes using water falling film dielectric barrier discharge. Journal of hazardous materials, 192(2), 763-771.

Enami, S., Hoffmann, M., \& Colussi, A. (2008). Acidity enhances the formation of a persistent ozonide at aqueous ascorbate/ozone gas interfaces. Proceedings of the National Academy of Sciences, 105(21), 7365-7369.

Gao, L., Sun, L., Wan, S., Yu, Z., \& Li, M. (2013). Degradation kinetics and mechanism of emerging contaminants in water by dielectric barrier discharge non-thermal plasma: the case of $17 \beta$ Estradiol. Chemical engineering journal, 228, 790-798.

García-Viguera, C., \& Bridle, P. (1999). Influence of structure on colour stability of anthocyanins and flavylium salts with ascorbic acid. Food Chemistry, 64(1), 21-26.

Garofulić, I. E., Jambrak, A. R., Milošević, S., Dragović-Uzelac, V., Zorić, Z., \& Herceg, Z. (2015). The effect of gas phase plasma treatment on the anthocyanin and phenolic acid content of sour cherry Marasca (Prunus cerasus var. Marasca) juice. LWT-Food Science and Technology, 62(1), 894-900.

González-Aguilar, G., Zavaleta-Gatica, R., \& Tiznado-Hernández, M. (2007). Improving postharvest quality of mango 'Haden'by UV-C treatment. Postharvest biology and technology, 45(1), 108116.

Grzegorzewski, F., Ehlbeck, J., Schlüter, O., Kroh, L. W., \& Rohn, S. (2011). Treating lamb's lettuce with a cold plasma-Influence of atmospheric pressure Ar plasma immanent species on the phenolic profile of Valerianella locusta. LWT-Food Science and Technology, 44(10), 22852289.

Heinonen, I. M., Meyer, A. S., \& Frankel, E. N. (1998). Antioxidant activity of berry phenolics on human low-density lipoprotein and liposome oxidation. Journal of agricultural and food chemistry, 46(10), 4107-4112.

Heo, N. S., Lee, M.-K., Kim, G. W., Lee, S. J., Park, J. Y., \& Park, T. J. (2014). Microbial inactivation and pesticide removal by remote exposure of atmospheric air plasma in confined environments. Journal of Bioscience and Bioengineering, 117(1), 81-85.

Hwang, E.-S., Cash, J. N., \& Zabik, M. J. (2001). Postharvest treatments for the reduction of mancozeb in fresh apples. Journal of agricultural and food chemistry, 49(6), 3127-3132.

Ikeura, H., Kobayashi, F., \& Tamaki, M. (2011). Removal of residual pesticide, fenitrothion, in vegetables by using ozone microbubbles generated by different methods. Journal of Food Engineering, 103(3), 345-349.

Karaca, H., Walse, S. S., \& Smilanick, J. L. (2012). Effect of continuous $0.3 \mu \mathrm{L} / \mathrm{L}$ gaseous ozone exposure on fungicide residues on table grape berries. Postharvest biology and technology, 64(1), 154-159.

Kogelschatz, U. (2007). Twenty years of Hakone symposia: from basic plasma chemistry to billion dollar markets. Plasma Processes and Polymers, 4(7-8), 678-681.

Lacombe, A., Niemira, B. A., Gurtler, J. B., Fan, X., Sites, J., Boyd, G., \& Chen, H. (2015). Atmospheric cold plasma inactivation of aerobic microorganisms on blueberries and effects on quality attributes. Food Microbiology, 46, 479-484.

Lagunas-Allué, L., Martínez-Soria, M.-T., Sanz-Asensio, J., Salvador, A., Ferronato, C., \& Chovelon, J. M. (2010). Photocatalytic degradation of boscalid in aqueous titanium dioxide suspension: Identification of intermediates and degradation pathways. Applied Catalysis B: Environmental, 98(3), 122-131.

Makris, D. P., \& Rossiter, J. T. (2002). Hydroxyl free radical-mediated oxidative degradation of quercetin and morin: a preliminary investigation. Journal of Food Composition and Analysis, 15(1), 103-113. 
Malato, S., Caceres, J., Agüera, A., Mezcua, M., Hernando, D., Vial, J., \& Fernández-Alba, A. (2001). Degradation of imidacloprid in water by photo-Fenton and TiO2 photocatalysis at a solar pilot plant: a comparative study. Environmental science \& technology, 35(21), 4359-4366.

Misra, N., Keener, K. M., Bourke, P., Mosnier, J.-P., \& Cullen, P. J. (2014). In-package atmospheric pressure cold plasma treatment of cherry tomatoes. Journal of Bioscience and Bioengineering, 118(2), 177-182.

Misra, N., Pankaj, S., Frias, J., Keener, K., \& Cullen, P. (2015). The effects of nonthermal plasma on chemical quality of strawberries. Postharvest biology and technology, 110, 197-202.

Misra, N., Pankaj, S. K., Walsh, T., O'Regan, F., Bourke, P., \& Cullen, P. J. (2014). In-package nonthermal plasma degradation of pesticides on fresh produce. Journal of hazardous materials, 271, 33-40.

Misra, N. N., Keener, K. M., Bourke, P., \& Cullen, P. J. (2015). Generation of In-Package Cold Plasma and Efficacy Assessment Using Methylene Blue. Plasma Chemistry and Plasma Processing, 114.

Misra, N. N., Keener, K. M., Bourke, P., Mosnier, J.-P., \& Cullen, P. J. (2014). In-package atmospheric pressure cold plasma treatment of cherry tomatoes. Journal of Bioscience and Bioengineering, 118(2), 177-182.

Misra, N. N., Patil, S., Moiseev, T., Bourke, P., Mosnier, J. P., Keener, K. M., \& Cullen, P. J. (2014). Inpackage atmospheric pressure cold plasma treatment of strawberries. Journal of Food Engineering, 125, 131-138.

Misra, N. N., Ziuzina, D., Cullen, P. J., \& Keener, K. M. (2013). Characterization of a novel atmospheric air cold plasma system for treatment of packaged biomaterials. Transactions of the ASABE, 56(3), 1011-1016.

Moiseev, T., Misra, N. N., Patil, S., Cullen, P. J., Bourke, P., Keener, K. M., \& Mosnier, J. P. (2014). Post-discharge gas composition of a large-gap DBD in humid air by UV-Vis absorption spectroscopy. Plasma Sources Science and Technology, 23(6), 065033.

Moldau, H. (1998). Hierarchy of ozone scavenging reactions in the plant cell wall. Physiologia Plantarum, 104(4), 617-622.

Pankaj, S. K., Bueno-Ferrer, C., Misra, N., Milosavljević, V., O'Donnell, C., Bourke, P., Keener, K., \& Cullen, P. (2014). Applications of cold plasma technology in food packaging. Trends in Food Science \& Technology, 35(1), 5-17.

Reddy, P. M. K., Mahammadunnisa, S., \& Subrahmanyam, C. (2014). Catalytic non-thermal plasma reactor for mineralization of endosulfan in aqueous medium: A green approach for the treatment of pesticide contaminated water. Chemical Engineering Journal, 238, 157-163.

Reynolds, G., Graham, N., Perry, R., \& Rice, R. (1989). Aqueous ozonation of pesticides: a review.

Sarangapani, C., Devi, Y., Thirundas, R., Annapure, U. S., \& Deshmukh, R. R. (2015). Effect of lowpressure plasma on physico-chemical properties of parboiled rice. LWT-Food Science and Technology.

Sarangapani, C., Misra, N., Milosavljevic, V., Bourke, P., O’Regan, F., \& Cullen, P. (2016). Pesticide degradation in water using atmospheric air cold plasma. Journal of Water Process Engineering, 9, 225-232.

Sarangapani, C., Thirumdas, R., Devi, Y., Trimukhe, A., Deshmukh, R. R., \& Annapure, U. S. (2016). Effect of low-pressure plasma on physico-chemical and functional properties of parboiled rice flour. LWT-Food Science and Technology, 69, 482-489.

Singleton, V. L., Orthofer, R., \& Lamuela-Raventos, R. M. (1999). [14] Analysis of total phenols and other oxidation substrates and antioxidants by means of folin-ciocalteu reagent. Methods in enzymology, 299, 152-178.

Stevens, C., Wilson, C., Lu, J., Khan, V., Chalutz, E., Droby, S., Kabwe, M., Haung, Z., Adeyeye, O., \& Pusey, L. (1996). Plant hormesis induced by ultraviolet light-C for controlling postharvest diseases of tree fruits. Crop Protection, 15(2), 129-134. 
Tappi, S., Gozzi, G., Vannini, L., Berardinelli, A., Romani, S., Ragni, L., \& Rocculi, P. (2016). Cold plasma treatment for fresh-cut melon stabilization. Innovative Food Science \& Emerging Technologies, 33, 225-233.

Tiwari, B. K., Muthukumarappan, K., O'Donnell, C. P., \& Cullen, P. (2008). Kinetics of freshly squeezed orange juice quality changes during ozone processing. Journal of agricultural and food chemistry, 56(15), 6416-6422.

Uckoo, R. M., Jayaprakasha, G. K., Somerville, J. A., Balasubramaniam, V., Pinarte, M., \& Patil, B. S. (2013). High pressure processing controls microbial growth and minimally alters the levels of health promoting compounds in grapefruit (Citrus paradisi Macfad) juice. Innovative Food Science \& Emerging Technologies, 18, 7-14.

Von Gunten, U. (2003). Ozonation of drinking water: Part I. Oxidation kinetics and product formation. Water research, 37(7), 1443-1467.

Wang, C. Y., Chen, C.-T., \& Wang, S. Y. (2009). Changes of flavonoid content and antioxidant capacity in blueberries after illumination with UV-C. Food Chemistry, 117(3), 426-431.

Wang, R., Nian, W., Wu, H., Feng, H., Zhang, K., Zhang, J., Zhu, W., Becker, K., \& Fang, J. (2012). Atmospheric-pressure cold plasma treatment of contaminated fresh fruit and vegetable slices: inactivation and physiochemical properties evaluation. The European Physical Journal $D, 66(10), 1-7$.

Winter, C. K., \& Katz, J. M. (2011). Dietary exposure to pesticide residues from commodities alleged to contain the highest contamination levels. Journal of toxicology, 2011.

Won, M. Y., Lee, S. J., \& Min, S. C. (2017). Mandarin preservation by microwave-powered cold plasma treatment. Innovative Food Science \& Emerging Technologies, 39, 25-32.

Wu, J., Luan, T., Lan, C., Lo, T. W. H., \& Chan, G. Y. S. (2007). Removal of residual pesticides on vegetable using ozonated water. Food Control, 18(5), 466-472.

Zhishen, J., Mengcheng, T., \& Jianming, W. (1999). The determination of flavonoid contents in mulberry and their scavenging effects on superoxide radicals. Food Chemistry, 64(4), 555559. 


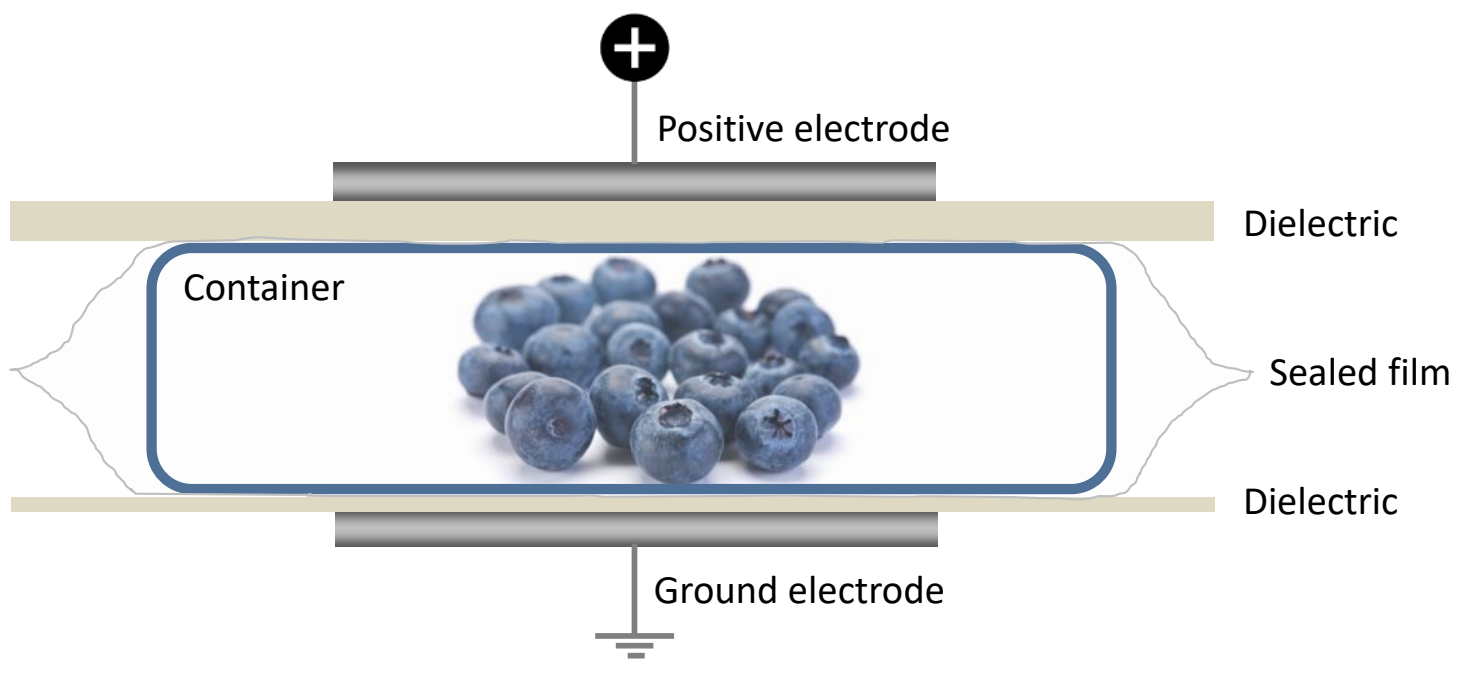

Fig. 1. Schematic of the experimental setup with electrical and optical diagnostics 

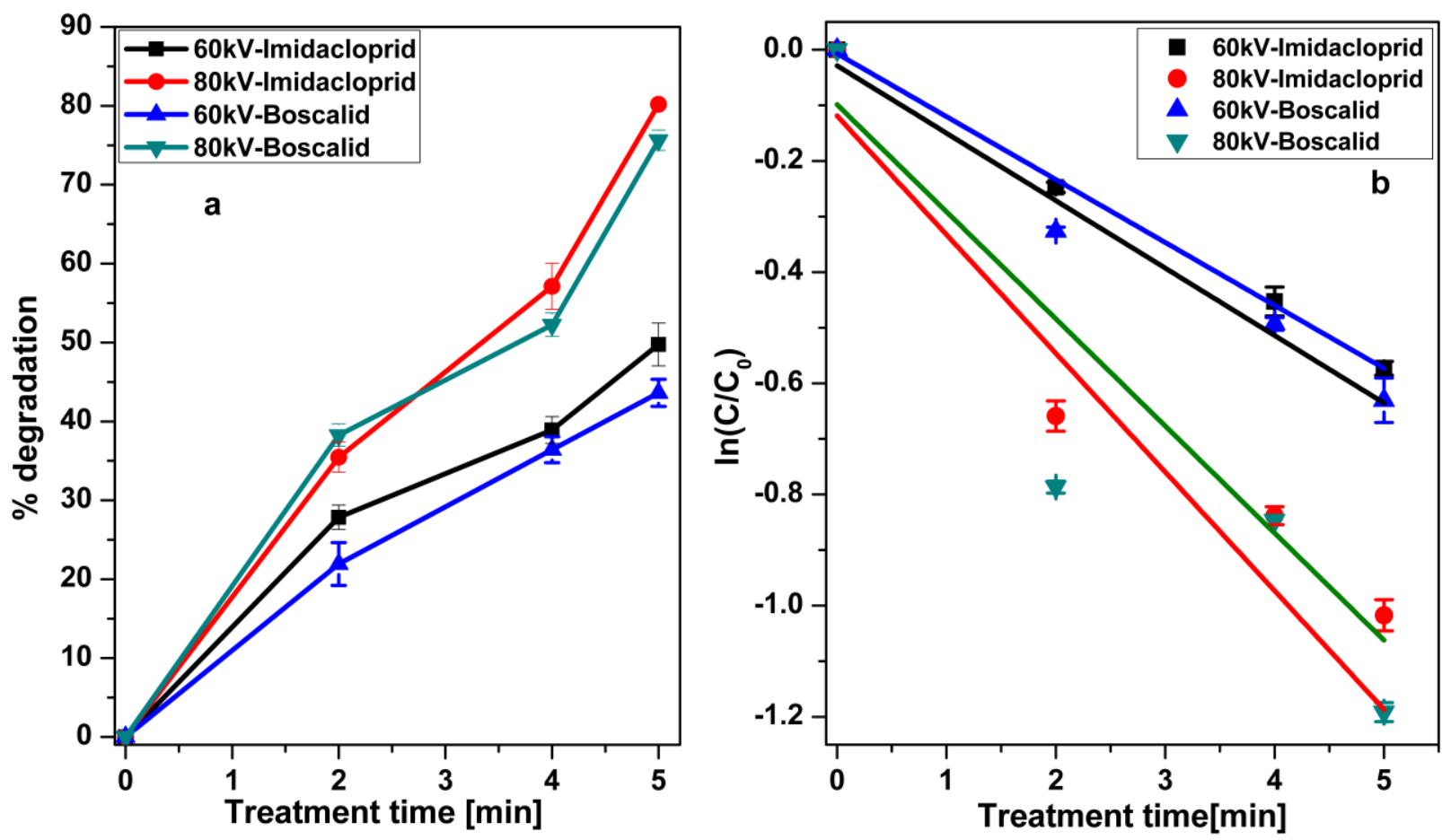

Fig.2. a) Time and voltage dependent degradation of pesticides on blueberries b) first-order degradation kinetic of boscalid and imidacloprid 


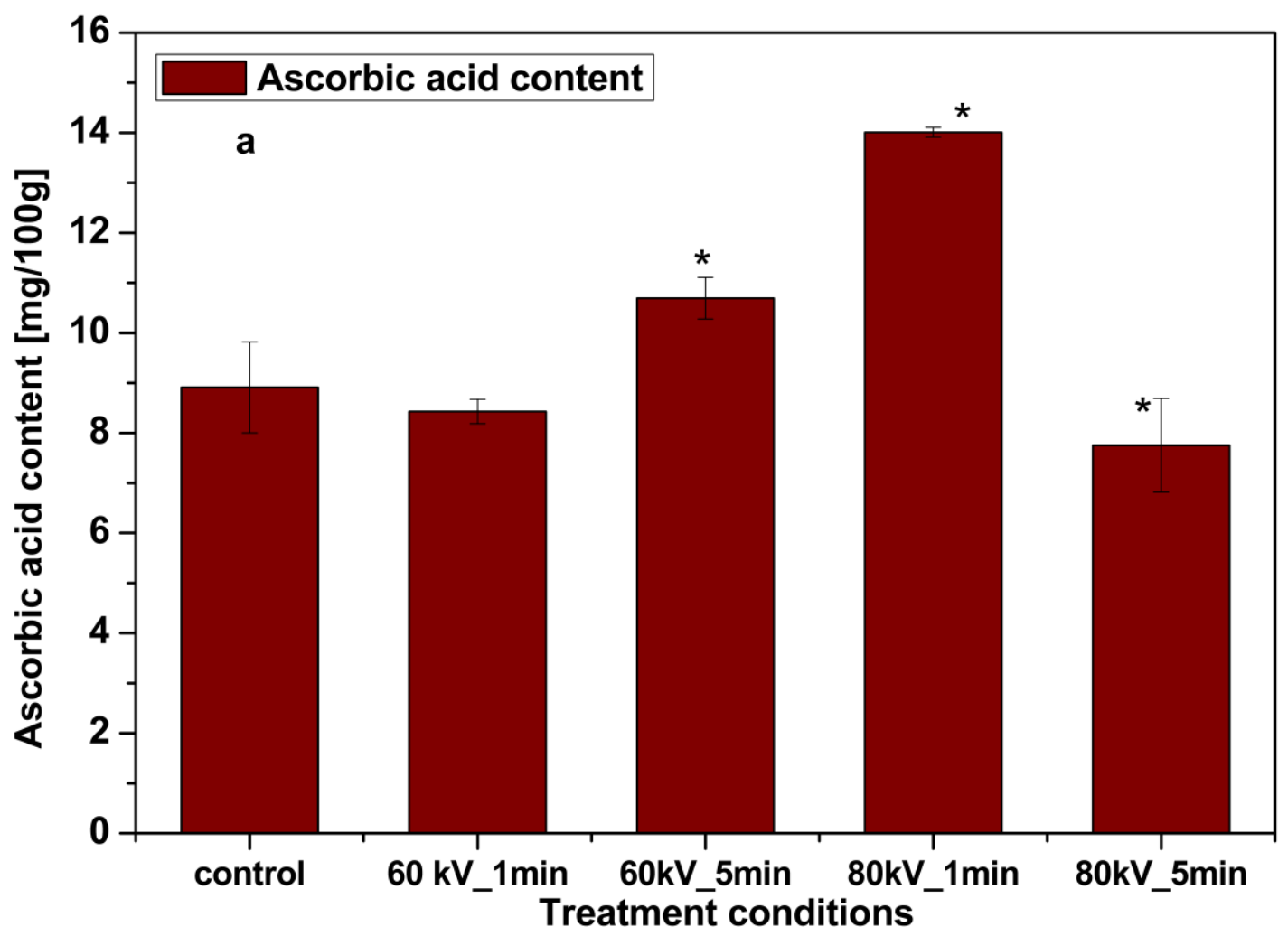




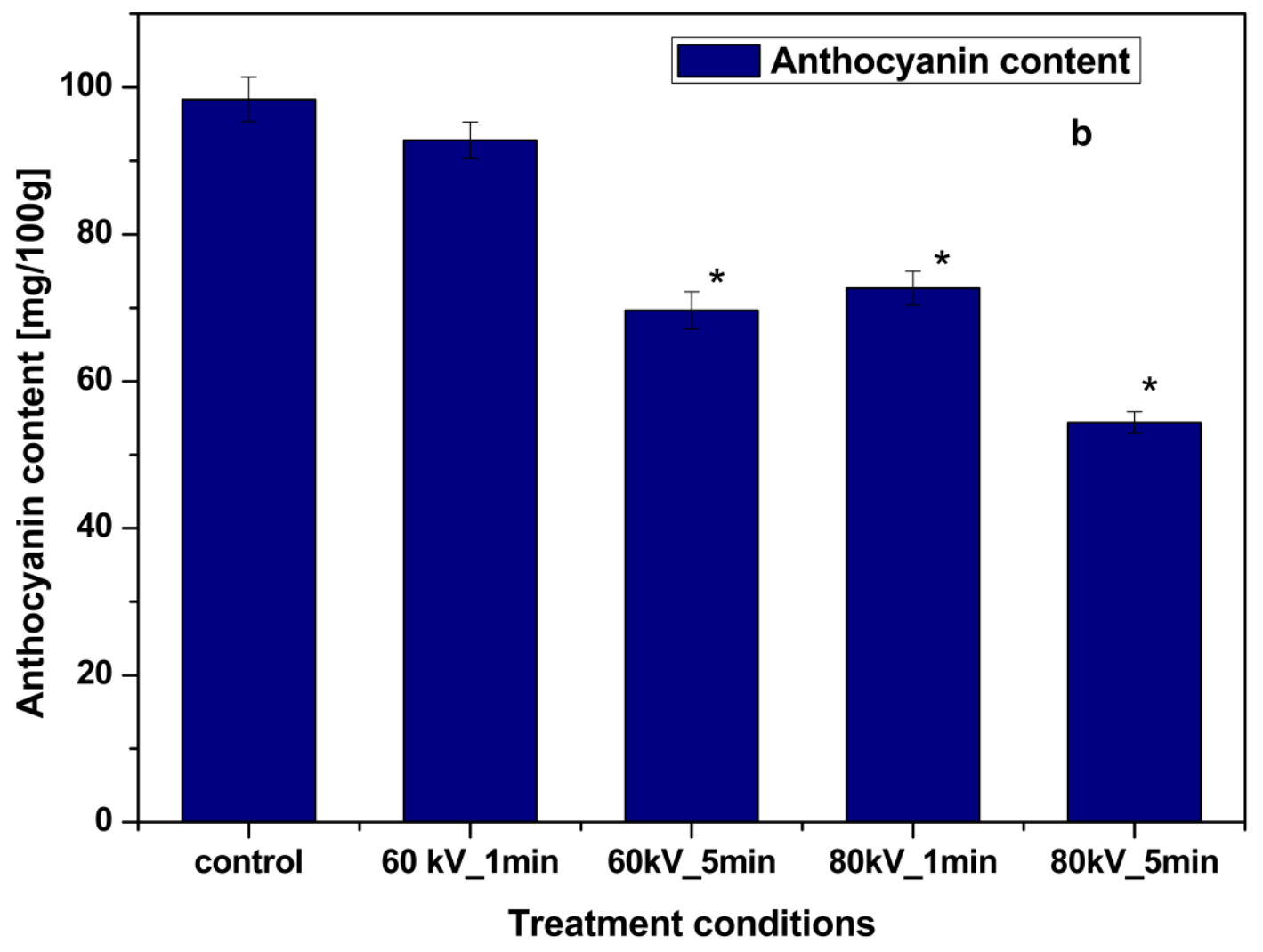

Fig.3. Changes in a) ascorbic acid content and b) anthocyanin content of control and cold plasma treated blueberries ( $24 \mathrm{~h}$ post-treatment); '*' indicates a statistically significant difference compared to control. In the data markers, the first digit indicates the voltage, the second time. 
Table 1 Model parameters for pesticide degradation based on first-order kinetics

\begin{tabular}{llll}
\hline Pesticide & Voltage $(\mathbf{k V})$ & Rate constant $\mathbf{k}\left(\mathbf{m i n}^{-1}\right)$ & $\mathbf{R}^{\mathbf{2}}(\mathbf{A d j})$ \\
\hline Boscalid & 60 & $0.121 \pm 0.001$ & 0.97 \\
& 80 & $0.213 \pm 0.054$ & 0.92 \\
Imidacloprid & 60 & $0.113 \pm 0.003$ & 0.99 \\
& 80 & $0.192 \pm 0.038$ & 0.91 \\
\hline
\end{tabular}


Table 2 Changes in physical quality parameters of control and cold plasma treated blueberries

\begin{tabular}{lllllll}
\hline $\begin{array}{l}\text { Treatment } \\
\text { Conditions }\end{array}$ & $\mathbf{L}^{*}$ & $\mathbf{a}^{*}$ & $\mathbf{b}^{*}$ & Firmness (N) & $\begin{array}{l}\text { Total soluble } \\
\text { solids }\left(^{\circ} \mathbf{b r i x}\right)\end{array}$ & Titrable acidity(meq/L) \\
\hline Control & $48.90 \pm 0.73^{\mathrm{a}}$ & $0.30 \pm 0.02^{\mathrm{a}}$ & $-1.19 \pm 0.03^{\mathrm{a}}$ & $1.92 \pm 0.11^{\mathrm{a}}$ & $12.40 \pm 0.10^{\mathrm{a}}$ & $17.0 \pm 0.21^{\mathrm{a}}$ \\
$60 \mathrm{kV} \_1 \mathrm{~min}$ & $47.56 \pm 1.44^{\mathrm{a}}$ & $0.29 \pm 0.02^{\mathrm{a}}$ & $-1.30 \pm 0.05^{\mathrm{a}}$ & $1.80 \pm 0.06^{\mathrm{a}}$ & $12.80 \pm 0.21^{\mathrm{b}}$ & $17.24 \pm 0.33^{\mathrm{a}}$ \\
$60 \mathrm{kV} \_5 \mathrm{~min}$ & $45.18 \pm 0.79^{\mathrm{a}}$ & $0.27 \pm 0.01^{\mathrm{a}}$ & $-1.33 \pm 0.04^{\mathrm{a}}$ & $1.03 \pm 0.07^{\mathrm{c}}$ & $13.50 \pm 0.30^{\mathrm{c}}$ & $16.90 \pm 0.12^{\mathrm{a}}$ \\
$80 \mathrm{kV} \_1$ min & $45.43 \pm 0.57^{\mathrm{a}}$ & $0.25 \pm 0.01^{\mathrm{a}}$ & $-1.31 \pm 0.17^{\mathrm{a}}$ & $1.30 \pm 0.08^{\mathrm{b}}$ & $13.24 \pm 0.62^{\mathrm{c}}$ & $17.25 \pm 0.37^{\mathrm{a}}$ \\
$80 \mathrm{kV} \_5 \mathrm{~min}$ & $43.76 \pm 0.86^{\mathrm{b}}$ & $0.23 \pm 0.06^{\mathrm{b}}$ & $-1.43 \pm 0.06^{\mathrm{b}}$ & $0.64 \pm 0.11^{\mathrm{d}}$ & $14.10 \pm 0.41^{\mathrm{d}}$ & $17.33 \pm 0.40^{\mathrm{a}}$
\end{tabular}

All the data are expressed as mean \pm standard deviations. Means with a different superscript letters in a column differ significantly ( $\mathrm{p}<0.05$ ). 
1 Table 3 Changes in total polyphenolic content (TPC) and total flavonoid content (TFC) of 2 control and cold plasma treated blueberries

3

\begin{tabular}{lll}
\hline Treatment Conditions & $\begin{array}{l}\text { Total polyphenolic content } \\
(\mathbf{m g} \text { GAE/100g FW) }\end{array}$ & $\begin{array}{c}\text { Total flavonoid content } \\
(\mathbf{m g} \text { CEQ/100 g FW) }\end{array}$ \\
\hline Control & $210.12 \pm 5.22^{\mathrm{c}}$ & $89.22 \pm 6.22^{\mathrm{c}}$ \\
$60 \mathrm{kV} \_1 \mathrm{~min}$ & $250.12 \pm 11.55^{\mathrm{a}}$ & $98.22 \pm 10.22^{\mathrm{a}}$ \\
$60 \mathrm{kV} \_5 \mathrm{~min}$ & $190.25 \pm 12.25^{\mathrm{d}}$ & $72.84 \pm 6.42^{\mathrm{d}}$ \\
$80 \mathrm{kV} \_1 \mathrm{~min}$ & $230.54 \pm 8.22^{\mathrm{b}}$ & $82.21 \pm 4.11^{\mathrm{b}}$ \\
$80 \mathrm{kV} \_5 \mathrm{~min}$ & $150.25 \pm 4.22^{\mathrm{d}}$ & $65.21 \pm 3.32^{\mathrm{d}}$ \\
\hline
\end{tabular}

4 All the data are expressed as mean \pm standard deviations. Means with the different superscript 5 letters in a column differ significantly $(\mathrm{p}<0.05)$. 